\title{
REGENERASI TEGAKAN Araucaria hunsteinii K. Schum. PADA HUTAN PENDIDIKAN ANGGORI MANOKWARI
}

\section{(Araucaria hunsteinii K. Schum. Stand Regeneration in Anggori Educational Forest of Manokwari)}

\author{
Benyamin Kossay ${ }^{1}$ dan Rudi A. Maturbongs ${ }^{1 凶}$ \\ Jurusan Kehutanan, Fakultas Kehutanan Universitas Papua Manokwari, Papua Barat, \\ 98314. Tlp/Fax: +62986211065 . \\ $\triangle$ Penulis Korespondensi: Email: ra.maturbongs@gmail.com \\ Diterima: 15 Juni 2019| Disetujui: 30 Agust 2019
}

\begin{abstract}
Abstrak
Penelitian ini bertujuan untuk melihat intensitas kehadiran tegakan Araucaria hunstenii pada tingkat semai yang tumbuh pada blok tanam dan faktor-faktor yang mempengaruhi jumlah kehadiran tegakan semai di bawah tegakan Araucaria hunsteinii di Hutan Pendidikan Anggori, Manokwari. Penelitian ini menggunakan metode sensus pada seluruh individu dengan teknik survei. Hasil penelitian menunjukan bahwa terdapat 154 individu pada tingkat semai dalam luasan blok tanam $2.275 \mathrm{~m}^{2}$ atau 0,23 ha. (kerapatan 0,06). Dari 25 plot yang diobservasi, 23 plot ditumbuhi individu tingkat semai jenis A. hunsteinii (frekuensi 0,92). Faktor yang paling berpengaruh terhadap kehadiran semai Araucaria hunsteinii adalah intensitas cahaya dan ketebalan serasah. Kedepannya, perlu menerapkan pemeliharaan intensif terhadap tegakan A. hunsteinii dengan cara pembersihan terutama lantai hutan sehingga memudahkan proses perkecambahan benih dan pertumbuhan anakan baru jenis $A$. hunsteinii.
\end{abstract}

Kata kunci: regenerasi, hutan tropis, hutan pendidikan, araucaria, pertumbuhan semai

\begin{abstract}
This study aims to notice a number of Araucaria hunstenii stand intensities at seedling stage that grows in several planted blocks as well as factors that affected the number of seedling growths under Araucaria hunsteinii mature stand in Anggori Education Forest of Manokwari. Census has been carried out in all established plots in order to identify all seedling individuals found through survey. The result pointed out about 154 established seedling plants in the block size of $2,275 \mathrm{~m}^{2}$ or 0.23 ha (density of 0.06). From 25 established plots, 23 have been growed by A. hunsteinii (frequency of 0.92). The most significant factor on the Araucaria hunsteinii appearance was light intensity and litter thickness. For the long run of establishment, intensive care and cleaning of forest floor are important approach to keep the seed available and spur regeneration of seeds.

Keywords: regeneration, tropical forest, educational forest, araucaria, seedling growth
\end{abstract}

\section{PENDAHULUAN}

Hutan merupakan salah satu sumberdaya alam yang ada di muka bumi ini yang keberadaannya mutlak diperlukan sebagai penentu kestabilan ekosistem dunia. Mengingat besarnya 
potensi hutan maka perlu adanya suatu usaha untuk dapat dimanfaatkan dan dikembangkan serta dilestarikan secara berkesinambungan (Renggi dkk. 2015). Selain memiliki manfaat yang besar, hutan memainkan peranan yang sangat penting dalam suatu ekosistem alam dan berpengaruh pada sumberdaya alam lainnya dan jika tidak dimanfaatkan atau dikelola dengan baik dapat menimbulkan dampak yang buruk bagi manusia seperti banjir, longsor, erosi, mengeringnya mata air dan menurunnya produktifitas lahan pertanian pada musim kemarau (Ardiyansah 2006).

Pelestarian sumber daya alam hayati dibedakan menjadi dua bagian yaitu secara in-situ yang berarti usaha pelestarian atau penangkaran sumber daya alam hayati yang dilaksanakan dengan memelihara di habitat aslinya. Sedangkan secara ex-situ adalah usaha pelestarian atau penangkaran sumber daya alam hayati yang dilaksanakan dengan memindahkan individu yang dilestarikan dari tempat tumbuh aslinya untuk di pelihara di tempat lain di luar habitat aslinya (Kementerian Lingkungan Hidup dan Kehutanan 2016).

Hutan Pendidikan Anggori (HPA) sebagai kawasan pelestarian ex-situ merupakan salah satu hutan dataran rendah di Kabupaten Manokwari yang mempunyai potensi flora dan fauna yang beragam dengan bentuk wilayah yang unik. Karena bentuk wilayah yang unik tersebut terutama struktur geologi dan dengan kepadatan vegetasi hutannya serta letaknya yang dekat dengan kota maka hutan ini disebut juga sebagai hutan lindung (pengatur tata air).

Pohon Araucaria hunsteinii yang di tanam di areal Hutan Pendidikan Anggori merupakan salah satu jenis flora endemik
Papua New Guinea, sebagai penghasil kayu perdagangan (bahan baku kertas, kayu lapis, meubel dan lain-lain) yang bernilai ekonomi cukup tinggi. Pohon ini termasuk dalam famili Araucariaceae dari genus Araucaria, memiliki tajuk yang berbentuk kerucut dan memberi kesan indah sehingga sering digunakan sebagai tanaman hias atau pohon hias ataupun sering digunakan pada kegiatankegiatan penghijauan (Orwa et al. 2009). Studi ini bertujuan untuk melihat berapa banyak jumlah anakan semai jenis Araucaria hunstenii yang tumbuh pada petak tanam tegakan jenis ini, dan faktorfaktor yang mempengaruhi jumlah semai di bawah tegakan Araucaria hunsteinii pada areal Hutan Pendidikan Anggori Manokwari.

\section{METODE PENELITIAN}

Penelitian ini dilakukan pada area konservasi ex-situ Arboretum Hutan Pendidikan Anggori yang dikelola oleh Fakultas Kehutanan Universitas Papua Manokwari yang berlangsung selama dua minggu pada bulan September tahun 2014. Adapun obyek dalam penelitian ini adalah meliputi potensi pertumbuhan tegakan alam dan permudaan semai $A$. hunsteiniii di areal HPA.

\section{Metode dan Teknik Penelitian}

Metode yang digunakan dalam penelitian ini adalah metode sensus dengan teknik survei. Kegiatan obsevasi meliputi pengumpulan data primer dan data sekundern dimana pengumpulan data primer dilakukan sepanjang jalur dengan arah patokan utara-selatan. Teknik penarikan unit contoh yang dilakukan berupa plot kontinyu (line plot sampling) dengan intensitas sampling 100\%. Panjang jalur pengamatan disesuaikan 
dengan keadaan blok pada area tanaman A. hunsteinii. Plot pengamatan $1-20$ masing-masing dibuat 10 meter persegi dan plot pengamatan $21-25$ dengan ukurannya yang berbeda. Di dalam jalur pengamatan dilakukan pengamatan semai A. hunsteinii dan mencatat data mikrohabitatnya.

\section{Variabel Penelitian}

1. Jumlah semai $A$. hunstenii dalam plotplot pengamatan

2. Frekuensi semai $=$ Jumlah plot berisi semai Jumlah seluruh plot

3. Kerapatan semai $=$ Jumlah semai dalam seluruh plot luas seluruh plot

4. Lingkungan : tumbuhan lain, ketebalan serasah, intensitas cahaya, suhu udara, kelembaban udara, $\mathrm{pH}$ tanah, dan kelembaban tanah.

\section{Analisis Data}

Data hasil pengamatan yang diperoleh dari lapangan diolah secara tabulasi dan dianalisis secara deskriptif dan disajikan dalam bentuk tabel dan gambar.

\section{HASIL DAN PEMBAHASAN}

\section{Tegakan Benih A. hunsteinii}

Tanaman A. hunsteinii yang ada di Hutan Pendidikan Anggori yang dikelola oleh Fakultas Kehutanan Universitas Negeri Papua adalah spesies pegunungan yang berasal dari Papua Nugini. Tegakan ini ditanam pada tahun 1956 oleh Lembaga Penelitian dan Pengembangan Pertanian Manokwari sewaktu masa pemerintahan Belanda. Pada waktu itu, lembaga penelitian dan pengembangan pertanian ini menjadi salah satu lembaga penelitian dan pengembangan pertanian terbesar di Pasifik dan cukup dikenal oleh dunia. Berbagai jenis pohon dan tanaman pertanian dari wilayah Indonesia dan negara lain dikoleksi oleh lembaga ini.

Ukuran blok tanaman A. hunsteinii di HPA yaitu berukuran $50 \mathrm{~m} \times 41 \mathrm{~m}$, bentuknya menyerupai trapesium. Untuk mengetahui luasnya maka digunakan dua cara yaitu:

1. Luas Persegi Panjang $=$ Panjang $\times$ Lebar $=50 \mathrm{~m} \times 41 \mathrm{~m}=2050 \mathrm{~m}^{2}$

Luas Segitiga $=1 / 2($ alas $) \times$ Tinggi $=\times 1 / 2 \times(9 \mathrm{~m}) \times 50 \mathrm{~m}=225 \mathrm{~m}^{2}$

Luas blok tanaman Araucaria hunsteinii

$$
=2275 \mathrm{~m}^{2}
$$

2. Luas Trapesium $=1 / 2 \times$ Jumlah sisi-sisi sejajar $\times$ Tinggi

$$
=1 / 2 \times(50 \mathrm{~m} 41 \mathrm{~m}) \times 50 \mathrm{~m}=2275 \mathrm{~m}^{2}
$$

Dengan demikian luas blok tanaman A. hunsteinii adalah $2275 \mathrm{~m}^{2}$ atau $2275 \mathrm{~m}^{2}: 10000 \mathrm{~m}^{2}$ $=0,2275$ ha.

Berdasarkan pengamatan lapangan, diketahui jumlah pohon $A$. hunsteinii sebanyak 121 pohon, dengan rincian 118 (kondisi baik) dan 3 pohon (kondisi terganggu). Pohon yang baik yaitu pohon yang utuh (tidak patah), ukuran diameter dan tinggi batang yang berimbang, dengan daun yang rimbun. Sebaliknya, pohon yang terganggu yaitu batangnya patah tengah, cabang-cabangnya juga mengalami patah akibat angin.

Hasil penelitian menunjukkan bahwa jalur 1 memiliki jumlah pohon terbanyak yakni sebanyak 40 individu, selanjutnya diikuti oleh jalur 2 dan 5 masing-masing terdapat 25 individu. Jalur 3 dan 4 
memiliki jumlah pohon berturut-turut 16 individu dan 15 individu, dan merupakan jumlah yang terendah. Sampai bulan September 2014, jumlah pohon $A$. hunsteinii yang masih bertahan hidup sebanyak 121 individu.

Luas blok tanaman adalah $2275 \mathrm{~m}^{2}$, jarak tanam $3 \mathrm{~m} \times 3 \mathrm{~m}$, maka jumlah bibit A. hunsteinii yang ditanam pada awalnya (tahun 1956) adalah sebanyak $\pm 2275 \mathrm{~m}^{2}$ : $9 \mathrm{~m}^{2}=252,77$ atau dibulatkan menjadi 253 bibit. Dibandingkan dengan pohon yang tumbuh sekarang maka terjadi pengurangan individu sebesar 253 bibit 121 pohon $=132$ individu pohon yang mati selama periode 1956 sampai 2014 (58 tahun). Dengan kata lain sekitar $52,17 \%(132 / 253 \times 100)$ bibit pohon $A$. hunsteinii yang mati dalam periode waktu 58 tahun. Tingginya angka kematian ini diduga akibat proses adaptasi klimatik pada tahap awal pertumbuhan karena jenis ini adalah jenis yang tumbuh pada ekosistem pegunungan Papua Nugini dengan elevasi antara $600-2000 \mathrm{~m}$ dpl. Setelah dewasa penyebab kematiannya adalah faktor tiupan angin yang menyebabkan pohon A. hunsteinii tumbang. Terjangan angin sering terjadi di wilayah Gunung Meja dan sekitarnya pada periode tertentu. Bila tiupan angin ini terjadi, banyak pohon alam dan tanaman yang tumbang di wilayah ini.

Penampilan tegakan Araucaria hunsteinii yang ada di Hutan Pendidikan Fahutan Unipa Anggori telah mengalami adaptasi klimatis yang panjang sejak tahun 1956 karena habitat aslinya adalah hutan perbukitan sampai hutan pegunungan dengan elevasi $2000 \mathrm{~m}$ dpl, sedangkan habitatnya yang sekarang di Anggori adalah hutan dataran rendah dengan elevasi kurang dari $100 \mathrm{~m}$ dpl.

\section{Deskripsi Tegakan $A$. hunsteinii}

Tegakan A. hunsteinii dapat mencapai tinggi $45 \mathrm{~m}$, dengan diameter berkisar 30-100 cm. Batangnya tegak lurus dan ditutupi dengan kulit kasar mengelupas berwarna coklatan, merah, keabu-abuhan, cabang-cabangnya menempel hampir tegak lurus ada yang menonjol ke bawah pada batang pokok. Tajuknya berbentuk kerucut, daunnya kecil-kecil berbentuk jarum yang berujung tajam (panjang $2 \mathrm{~cm}$ dan lebar $1 \mathrm{~cm}$ ). Helaian daun terdiri dari serat-serat, tidak memiliki tangkai daun. Bergetah bening dan beraroma harum. Buahnya berbentuk runjung sampai bulat melonjong (Orwa et al. 2009). Musim berbuah bulan Juni - September, runjung buah matang jatuh pada bulan November. Buahnya memiliki diameter $41 \mathrm{~cm}$, berat $1,2 \mathrm{~kg}$, di dalam buah terdapat 758 biji. Bentuk biji seperti sayap kupu-kupu, sangat tipis, lebar $7 \mathrm{~cm}$ sampai $9 \mathrm{~cm}$. Runjung buah muda yang jatuh akibat tiupan angin kencang dan biji yang dihitung dari runjung buah muda dapat dilihat pada Gambar 1.

Pada pengamatan lapangan dijumpai terdapat tiga pohon $A$. hunsteinii yang batangnya patah tengah akibat badai angin, tetapi kondisinya masih hidup karena terdapat tunas-tunas baru yang muncul dari batang utamanya. Namun di masa yang akan datang diperkirakan jumlah pohon $A$. hunsteinii yang ada di lokasi Arboretum Hutan Pendidikan Anggori akan berkurang karena tumbang akibat badai angin yang sering terjadi secara periodik di daerah Manokwari ini dan juga faktor umur tegakan yang sudah cukup tua. 


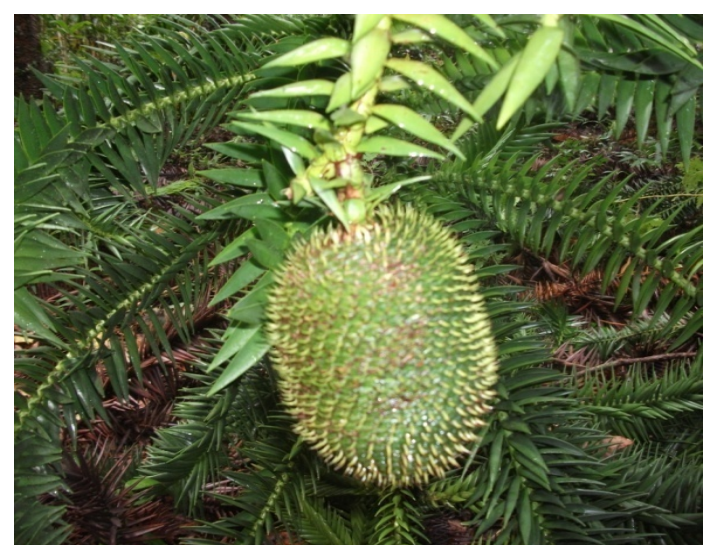

Gambar 1(a). Runjung buah muda

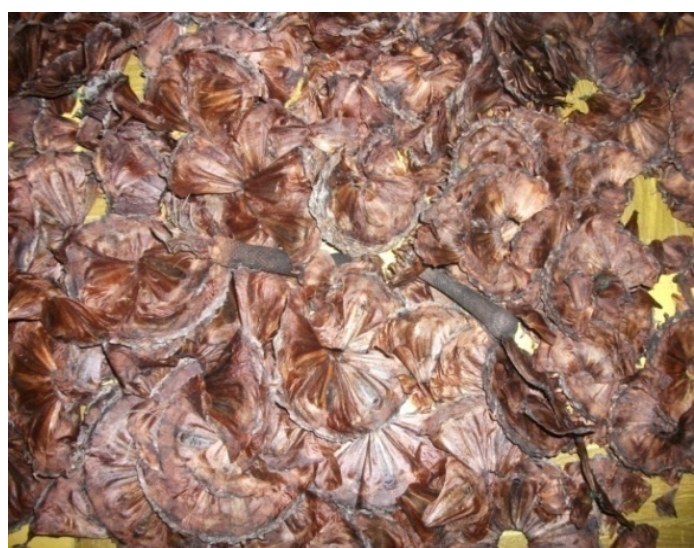

Gambar 1(b). Biji buah ( \pm 758 biji muda)

\section{Kondisi Semai Araucaria hunsteinii}

Kondisi pertumbuhan pada tingkat semai A. hunsteinii di Hutan Pendidikan Anggori terlihat cukup banyak dengan jumlah anakan tingkat semai $A$. hunsteinii pada blok tanaman sebanyak 154 anakan semai dengan luasan $2275 \mathrm{~m}^{2}$ atau 0,23 ha. Bila tegakan A. hunsteinii ini berada pada luasnya 1 ha maka akan terdapat \pm 669,6 atau 670 semai. Berdasarkan pengamatan di lapang, biji A. hunsteinii sangat mudah diperoleh dan cukup banyak tersedia di bawah tegakan, namun hanya sedikit saja yang berhasil tumbuh di bawah tegakan. Banyak faktor yang dapat mempengaruhi tingkat keberhasilan berkecambah benih $A$. hunsteinii yang jatuh di bawah tegakan. Buah tua yang jatuh di bawah tegakan berisi biji-biji yang fertile (dapat berkecambah) sehingga perlu dikumpulkan dan dibuatkan persemaian buatan untuk meningkatkan persentase keberhasilan perkecambahannya. Pohon induknya telah beradaptasi dengan baik pada hutan dataran rendah sehingga jenis ini dapat dikembangkan sebagai hutan tanaman dataran rendah. Tegakan A. hunsteinii di lokasi penelitian dapat dijadikan tegakan benih dengan catatan perlu dikelola secara intensif.

Semai A. hunsteinii yang ditemukan pada blok pengamatan sebanyak 154 semai dengan frekuensi 0,92 karena dijumpai dalam 23 plot dari 25 plot yang diamati. Pengamatan jumlah semai terbanyak ditemukan pada jalur 1 plot 3, dengan jumlah semai sebanyak 18 semai. Sementara jumlah semai terendah ditemukan pada jalur 4 plot 4 dan jalur 5 plot 1 dengan jumlah individu tingkat semai sebanyak 2 individu. Bahkan ada juga plot pengamatan yang tidak terdapat semai A. hunsteinii yakni jalur 4 plot 5 dan jalur 5 plot 5 . Untuk menjelaskan fakta-fakta di lapangan ini maka perlu dilakukan pengamatan dan analisis variabel-variabel habitat (lingkungan) semai A. hunsteinii tersebut.

\section{Lingkungan Tumbuh Tegakan Semai A. hunsteinii}

Lingkungan habitat adalah suatu sistem yang kompleks dimana berbagai faktor berpengaruh timbal balik satu sama lain terhadap suatu jenis tumbuhan. Berikut adalah variabel habitat (lingkungan) tegakan semai $A$. hunsteinii 
yang diukur dan diamati pada blok tanaman.

\section{Tumbuhan Bawah}

Tegakan semai A. hunsteinii tumbuh bersama-sama dengan tumbuhan bawah lainnya yaitu dari jenis alang-alang (Imperata cylindrica), semai mahoni (Switenia sp.), lengkuas hutan (Zingiberaceae), semai matoa (Pometia sp.), Selaginella sp. (Pterydophyta), dan tumbuhan liana. Jenis tumbuhan bawah yang tumbuh bersama-sama tegakan semai A. hunsteinii berkisar antara $2-3$ jenis dalam setiap plot (total tumbuhan bawah \pm 6 jenis). Kehadiran tumbuhan bawah memberikan perlindungan terhadap semai $A$. hunsteinii sehingga kelembaban tanah dan kelembaban udara yang sesuai untuk pertumbuhan tegakan semai A. hunsteinii.

\section{Ketebalan Serasah}

Hasil penelitian memperlihatkan bahwa tegakan semai $A$. hunsteinii tumbuh di lantai hutan dengan ketebalan serasah berkisar antara $14-28 \mathrm{~cm}$, namun semai $A$. hunsteinii cenderung menyukai habitat dengan ketebalan serasah antara $14-17 \mathrm{~cm}$ karena pada kisaran ketebalan serasah tersebut, jumlah semai terlihat lebih banyak. Ketebalan serasah yang ideal yaitu $14-17 \mathrm{~cm}$ karena menjaga kelembaban tanah dan suhu yang memadai untuk perkecambahan dan pertumbuhan tegakan semai. Bila ketebalan serasah meningkat, maka semakin menjauhkan benih $A$. hunsteinii dari tanah, bahkan memblok (menghalangi) perakaran semai untuk mencapai tanah pada proses pertumbuhan kecambah. Tipe perkecambahan $A$. hunsteinii yaitu perkecambahan epigeal yakni menjangkarkan semai dengan perakaran melalui perpanjangan hypocotyl yang cepat yang condong mengarah ke atas permukaan tanah dan kemudian menjadi tegak. Secara bersamaan cotyledon dan plumule muncul, dengan atau tanpa pelindung biji (seedcoat) masih melekat.

Biji yang jatuh di bawah pohon induk tidak mampu bertahan lama karena biji A. hunsteinii berbentuk pipih seperti sayap kupu-kupu, ringan, lebarnya 7-9 cm sehingga mudah mengalami dehidrasi (kehilangan kadar air) yang menyebabkan kematian benih. Hanya benih-benih yang berkualitas sangat baik dan benih-benih yang jatuh pada tanah dengan lapisan serasah yang tipis yang selanjutnya dapat tumbuh. Buah-buah tua yang jatuh di bawah tegakan perlu dipanen atau dikumpulkan, selanjutnya dibuat pesemaian untuk mengecambahkan bijibiji tersebut, sehingga dapat dihasilkan bibit A. hunsteinii secara memadai yang dapat digunakan untuk regenerasi selanjutnya.

\section{Intensitas Cahaya}

Intensistas cahaya pada blok tanaman Araucaria hunsteinii di lokasi HPA cukup bervariasi. Terlihat dari hasil pengukuran bahwa intensitas cahaya pada blok tanaman berkisar dari 39 - 1980 lux. Enright (1982) menyatakan bahwa tegakan semai $A$. hunsteinii adalah tumbuhan yang sangat memerlukan sinar matahari untuk petumbuhan yang ideal. A. hunsteinii lebih membutuhkan sinar matahari dibandingkan A. cuninghami. Secara umum, jenis A. hunsteinii tidak dapat melakukan regenerasi pada tajuk yang tertutup.

\section{Suhu Udara $\left({ }^{\circ} \mathrm{C}\right)$}

Suhu udara di blok tegakan $A$. hunsteinii berkisar antara $24{ }^{\circ} \mathrm{C}-29^{\circ} \mathrm{C}$. Kisaran suhu ini dapat memberikan 
dukungan pertumbuhan tegakan semai $A$. hunsteinii yang baik. Kisaran suhu pada lokasi penelitian menjadi faktor penting pemacu proses fisiologis dalam biji untuk berkecambah dan berkembang menjadi individu baru (Russo and Briscoe 2002).

Kelembaban Udara (\%)

Kelembaban udara pada blok tanaman A. hunsteinii berkisar antara $64 \%-73 \%$. Pada lokasi pengamatan, terlihat bahwa apabila nilai kelembaban semakin tinggi, ada kecenderungan jumlah semai semakin banyak (Russo and Briscoe 2002). Pada saat pengukuran kelembaban udara, wilayah Manokwari sedang berada pada musim panas karena tidak terjadi hujan lebih dari dua minggu. Kelembaban udara sangat penting dalam menunjang proses perkecambahan biji yang ada di bawah tegakan karena menjaga agar kandungan air dalam biji tetap stabil tidak mengalami dehidrasi (kehilangan air) yang dapat menyebabkan kekeringan dan kerusakan biji.

\section{pH Tanah}

Kondisi pH tanah di bawah tegakan $A$. hunsteinii pada Kawasan HPA di berkisar antara 5,2-6,6. Nilai ini berarti bahwa tegakan semai $A$. hunsteinii dapat tumbuh dengan baik pada kondisi kisaran $\mathrm{pH}$ tanah tersebut yakni agak masam sampai mendekati netral 6,6 (Russo and Briscoe 2002). Terdapat dua plot yaitu plot 4,5 dan 5,5 yang tidak ditumbuhi semai $A$. hunsteinii, yang mana $\mathrm{pH}$ tanah pada kedua plot tersebut berturut-turut 5,8 dan 6,4 . Kondisi ini menunjukkan bahwa ada faktor lain yang menyebabkan ketidakhadiran pertumbuhan semai $A$. hunsteinii pada kedua plot tersebut.

\section{Kelembaban Tanah}

Dari pengukuran parameter kelembaban tanah, nampak bahwa semai $A$. hunsteinii tumbuh pada tanah dengan indeks kelembaban tanah berkisar $2-5$ (kering agak lembab) (Russo and Briscoe 2002). Nilai indeks tersebut menunjukkan bahwa kadar air dalam tanah sangat rendah karena factor lamanya tidak terjadi hujan yang membasahi tanah hutan. Kondisi tanah yang kering dalam waktu lama dapat menyebabkan kematian semai karena tidak tersedia air untuk kebutuhan proses fisiologi dalam pertumbuhan.

\section{Perambahan Tegakan Semai $A$. hunsteinii}

Rendahnya jumlah populasi tegakan semai A. hunsteinii di plot pengamatan selain dipengaruhi faktor mikro-habitat, juga disebabkan oleh tingkat pengambilan jenis anakan (semai) oleh masyarakat. Kondisi ini menyebabkan jumlah tegakan semai yang ada hanya terlihat cukup sedikit. Hal ini terindikasi dari adanya jejak pengambilan semai berupa galian tanah yang ditumbuhi semai $A$. hunsteinii dan adanya semai yang telah lama ditanam sebagai tanaman hias di rumah masyarakat.

Kondisi tegakan A. hunsteinii di Kawasan HPA dapat dijadikan sumber benih dengan syarat perlu dikelola secara intensif sehingga dapat menghasilkan bibit yang memadai untuk memenuhi berbagai keperluan seperti bibit untuk hutan tanaman dan tanaman penghijauan karena jenis ini dapat menciptakan laju infiltrasi tinggi di bawah tegakan.

\section{DAFTAR PUSTAKA}

Ardiyansah H. 2006. Perbedaan laju infiltrasi di bawah tegakan Tectona grandis dan Araucaria klinkii pada Kebun Percobaan Anggori Manokwari. Skripsi Sarjana 
Kehutanan Universitas Negeri Papua. Manokwari (tidak diterbitkan).

Enright NJ. 1982. The ecology of Araucaria species in New Guinea. I. Ordination studies of forest types and environments. Austral Ecology, 7 (1): 23-38.

Kementerian Lingkungan Hidup dan Kehutanan. 2016. Laporan kinerja direktorat jenderal KSDAE tahun 2015. Direktorat Jenderal Konservasi Sumber Daya Alam dan Ekosistem, Kementerian Lingkungan Hidup dan Kehutanan, Jakarta.

Orwa C, Mutua A, Kindt R, Jamnadass R and Anthony S. 2009. Agroforestry database: a tree reference and selection guide version 4.0. http://old.worldagroforestry.org/treedb /AFTPDFS/Araucaria_cunninghamii.P DF.

Renggi ER, Indra $\mathrm{M}$, Muslich $\mathrm{M}$ dan Asmui. 2015. Pengelolaan sumber daya hutan dan pemanfaatan mekanisme pembayaran layanan ekosistem di hutan adat. Buku Panduan. Aliansi Masyarakat Adat Nusantara dan Japan Social Development Fund.

Russo RO and Briscoe CB. 2002. Performance of Klinki (Araucaria hunsteinii K. Schuman) in the humid tropics of Costa Rica. Journal of Sustainable Forestry, 14 (4): 13-18. 